\title{
Hydrogen isotope retention in plasma-facing materials: \\ Review of recent experimental results
}

\author{
V.Kh. Alimov ${ }^{1}$, J. Roth ${ }^{2}$ \\ ${ }^{1}$ Institute of Physical Chemistry and Electrochemistry, Russian Academy of Sciences, \\ Leninsky prospect 31, 119991 Moscow, Russia \\ ${ }^{2}$ Max-Planck-Institut für Plasmaphysik, EURATOM Association, \\ Boltzmannstrasse 2, D-85748 Garching, Germany
}

PACS Ref: 52.77.Dq

\begin{abstract}
Recent data on deuterium retention in carbon fibre composites and tungsten both irradiated with D ions and exposed to D plasmas are presented. Deuterium depth profiles measured up to depths of 7-14 $\mu \mathrm{m}$ allow understanding the mechanism which is responsible for the hydrogen isotope trapping in these materials.

In the CFC materials the amount of retained deuterium increases with the ion fluence at all irradiation temperatures in the range from 323 to $723 \mathrm{~K}$. No saturation is reached as observed in pyrolytic graphite. Depth profiles show that saturation occurs only within a near surface layer corresponding to the ion range. The increase in total retention at near-room temperature is accompanied by an increasing of the long profile tail extending beyond $14 \mu \mathrm{m}$ with the D concentration of about $10^{-1}$ at.\% at a depth of $10 \mu \mathrm{m}$ for fluences above $10^{24} \mathrm{D} / \mathrm{m}^{2}$.

The depth at which deuterium is retained in $\mathrm{W}$ can be divided into three zones: (i) the near-surface layer (up to a depth of 0.2-0.5 $\mu \mathrm{m}$ depending on ion energy), (ii) the sub-surface layer (from $\sim 0.5$ to $\sim 2 \mu \mathrm{m}$ ), and (iii) the bulk (>5 $\mu \mathrm{m}$ ). Low-energy D ion irradiation modifies the $\mathrm{W}$ structure to depths of up to about $5 \mu \mathrm{m}$, both for $\mathrm{W}$ single crystals and polycrystalline $\mathrm{W}$. The high $\mathrm{D}$ concentration (0.1-0.3 at.\%) at depths of 1-3 $\mu \mathrm{m}$ relates to accumulation of $\mathrm{D}_{2}$ molecules in vacancy clusters and voids. These defects are supposed to be generated due to plastic deformation of the $\mathrm{W}$ surface caused by deuterium supersaturation within the near-surface layer.
\end{abstract}

\section{Introduction}

The use of tritium (T) in nuclear fusion reactors must be carefully controlled due to its radioactivity and due to fuel economy reasons. The quantification of the tritium inventory 
depends on an accurate knowledge of the processes of retention and release of hydrogen isotopes from plasma-facing materials (PFMs). Designs for next generation fusion machines such as ITER employ several PFMs selected for their suitability to regions of the vessel with different power and flux characteristics, namely carbon based materials, beryllium (Be), tungsten (W).

The topic of hydrogen isotope retention and recycling in the PFMs has been reviewed previously [1-3]. For Be, the data base on hydrogen retention was established before 1999. The hydrogen retention rate is high at low ion fluences and decreases practically to zero at high fluences, similar to that in pyrolytic graphite. Depth profiles show retention within the ion range and no indication for hydrogen diffusion into the bulk of Be at temperatures below $500 \mathrm{~K}$.

Because of its favourable thermo-mechanical properties carbon fibre composites (CFC) are widely used as plasma-facing components in present fusion experimental machines like JET, TFTR, JT-60U, Tore Supra, Textor... etc, and currently are the candidate material for the vertical targets of the divertor plates of ITER. Tungsten is considered to be one of the important candidates for the divertor materials due to its good low erosion and thermal properties at high temperatures. Thus, data related to long-term plasma-CFC/W interactions are extremely important.

Deep penetration of deuterium into carbon fibre composite CF222 (up to 2-3 mm) was reported after its exposure to the PISCES-A plasma [4]. Tritium depth profiles in divertor tiles retrieved from TFTR and JET have revealed that in the 2D (two-dimensional) CFC tiles from JET a large fraction of tritium (in the average about 40\%) was retained at depths larger than 1 $\mathrm{mm}$ in comparison to only few percent found at these depths in the 4D CFC tile from TFTR [57]. The most probable mechanism involves tritium migration between woven sheets of the $2 \mathrm{D}$ CFC [6]. The relatively high values of apparent diffusion coefficient for tritium in 2D CFC CX$2002 \mathrm{U}\left(1.7 \times 10^{-16} \mathrm{~m}^{2} / \mathrm{s}\right.$ at $293 \mathrm{~K}$ and $2.3 \times 10^{-15} \mathrm{~m}^{2} / \mathrm{s}$ at $\left.573 \mathrm{~K}\right)$ were derived from the autoradiograph data representing the tritium concentration in the CFC samples exposed to $\mathrm{D} / \mathrm{T}$ RF plasma [8].

Most of the results on hydrogen isotope retention and recycling for tungsten have been reviewed by Causey and Venhaus [2, 3]. However, not much is known about the hydrogen retention in different $\mathrm{W}$ materials exposed to low-energy and high-flux hydrogen plasma. Available data [9-15] have shown that the hydrogen isotope retention for the case of high-flux hydrogen plasma exposure differs from that for ion implantation.

The paper presents recent experimental results on the deuterium retention in carbon fibre composites and W materials both irradiated with D ions and exposed to D plasmas. 


\section{Experimental}

The experimental studies described below were performed at Max-Planck-Institut für Plasmaphysik, Garching (IPP), Institute of Physical Chemistry and Electrochemistry, Moscow (IPCE), and University of California - San Diego (UCSA).

The CFC and W samples were subjected to D ion irradiation and D plasma exposure. The irradiation with $200 \mathrm{eV}$ D ions was performed at IPP Garching in a vacuum chamber connected to a high-current ion source [16] at normal ion incidence. The irradiation of CFC and polycrystalline $\mathrm{W}$ materials was performed with ion flux of $(3.6 \pm 1.1) \times 10^{19} / \mathrm{m}^{2} \mathrm{~s}$, whereas W single crystal was bombarded with ion flux of $(1.9 \pm 0.2) \times 10^{18} \mathrm{D} / \mathrm{m}^{2} \mathrm{~s}$. By electron bombardment from the rear the temperature could be varied from 323 to $723 \mathrm{~K}$.

The samples were also exposed to a deuterium plasma generated in a planar dc magnetron with a bias of $450 \mathrm{~V}$ [17]. Considering that $\mathrm{D}_{2}{ }^{+}$ions dominate in the plasma, the mean energy of $\mathrm{D}$ ions was estimated to be approximately $200 \mathrm{eV}$. The ion flux was determined from ion current measurements to $(1.1 \pm 0.2) \times 10^{21} \mathrm{D} / \mathrm{m}^{2} \mathrm{~s}$. During plasma exposure the sample temperature was measured by a chromel-alumel thermocouple attached to the front surface of the sample outside the irradiation area. The variation of the sample temperature was $\pm 15 \mathrm{~K}$.

CFC N11 samples were exposed to low-energy (about 100-150 eV/D) and high-flux (about $2 \times 10^{22} \mathrm{D} / \mathrm{m}^{2} \mathrm{~s}$ ) deuterium plasmas in PISCES-A (UCSD) [18]. Temperatures of 473 and $673 \mathrm{~K}$ were achieved by varying the plasma parameters and consequently the ion flux.

The deuterium retention in the CFC and $\mathrm{W}$ materials was monitored using thermal desorption spectrometry (TDS), whereas deuterium depth profiles were determined by the

$\mathrm{D}\left({ }^{3} \mathrm{He}, \mathrm{p}\right){ }^{4} \mathrm{He}$ nuclear reaction in a resonance-like technique (NRA) [19]. The D concentration was measured by means of the $\mathrm{D}\left({ }^{3} \mathrm{He}, \alpha\right) \mathrm{H}$ reaction, where both, the $\alpha$ particles and protons were analyzed. To determine the D concentration at larger depths, an analyzing beam of ${ }^{3} \mathrm{He}$ ions with energies varied from 0.69 to $4.0 \mathrm{MeV}$ was used.

\section{Carbon fibre composites}

Three-dimensional CFC NB31 (density $\rho=1.9 \mathrm{~g} / \mathrm{cm}^{3}$, open porosity $=8 \%$ ) and N11 $(\rho=$ $1.71-1.78 \mathrm{~g} / \mathrm{cm}^{3}$, open porosity $=12 \%$ ) provided by SEP (Bordeaux, France) were irradiated with 30 to $200 \mathrm{eV}$ D ions, both from ion beams and plasmas in PISCES-A and magnetron plasma device. 


\subsection{D inventories and depth profiles}

TDS shows that the amount of deuterium trapped in the CFC materials increases with the ion fluence, $\Phi$, at all irradiation temperatures in the range from 323 to $723 \mathrm{~K}$ (Fig. 1). In the case of $200 \mathrm{eV}$ D ion irradiation at room temperature, the retention increase proceeds proportional to $\Phi^{0.5}$ at high ion fluences. No saturation was reached as observed in pyrolytic graphite [20]. At a temperature of 473-523 K very similar retention values are obtained, while at $723 \mathrm{~K}$ the retention decreases by about a factor of 3 . The deuterium retention for $30 \mathrm{eV} \mathrm{D}$ ions proceeds as for $200 \mathrm{eV} \mathrm{D}$ ions, the absolute values being a factor of 3 lower. The data are not shown in Fig. 1 for clarity.

Very similar retention behaviour was found for the CFC N11 exposed to the PISCES-A plasma. Data for a bias voltage of $150 \mathrm{eV}$ and temperatures of 463 and $673 \mathrm{~K}$ are also introduced in Fig. 1. As the targets were heated by the incident plasma beam the temperature was not stable throughout the implantation and varied by $\pm 50 \mathrm{~K}$. This may be the reason for the relatively large scatter of the data. Even at the highest fluences of about $2 \times 10^{26} \mathrm{D} / \mathrm{m}^{2}$ no saturation is reached and increasing inward diffusion of D is observed in the depth profiles. The relatively low D retention in the CFC N11 exposed to the PISCES-A plasma at $473 \mathrm{~K}$, as compared to the CFC NB31 irradiated with D ions, can only partly be explained by the lower ion energies. Another factor may be the much shorter irradiation times at the higher fluxes leading to shorter migration distance than in the case of the ion irradiation.

In the CFC NB31 irradiated at $323 \mathrm{~K}$ with $200 \mathrm{eV} \mathrm{D}$ ions, the $\mathrm{D}$ depth profile is characterized by a near-surface maximum and by a long diffusion tail into the bulk, increasing with ion fluence (Fig. 2). The maximum D concentration in the near-surface layers is about 10 at.\%. Taking into consideration the roughness of the CFC surface and finite depth resolution of the NRA technique, the actual D surface concentration may be higher. Depth profiles show that saturation occurs only within a near surface layer equivalent to the ion range which widens as the fluence increases. For the fluences above $5 \times 10^{24} \mathrm{D} / \mathrm{m}^{2}$, the tail extends beyond $14 \mu \mathrm{m}$ with a D concentration around $10^{-1}$ at.\% at a depth of about $10 \mu \mathrm{m}$. A comparison of the D depth profiles in the pyrolytic graphite HPG and CFC NB31 irradiated with $200 \mathrm{eV} \mathrm{D}$ ions at $323 \mathrm{~K}$ to the practically same fluence (Fig. 2) demonstrates clearly that the structure of the carbon fibre composite is responsible for deuterium to penetrate into the bulk even at room temperature since no diffusion tail is observed in the pyrolytic graphite.

An increase of the irradiation temperature leads to a decrease of the $\mathrm{D}$ concentration both in the near-surface layers and in the bulk of the CFC NB31 (Fig. 3). It should be noted that the lengths of the profile tails for the same fluence only weakly depend on the irradiation temperature. The total amount of deuterium trapped in the CFC materials is obtained from the 
integration of the depth profile and decreases strongly with the irradiation/exposure temperature. With increasing irradiation/exposure temperature from 323 to about $950 \mathrm{~K}$, the D content decreases by about one order of a magnitude.

\subsection{Diffusion of D in CFC}

Based on the measured depth profiles, it is possible to estimate the coefficients of D migration in the CFC materials, assuming that the migration process can be treated like a diffusional process. If a constant deuterium concentration $C_{0}$ is maintained at the surface (or in a thin near-surface layer), the $\mathrm{D}$ concentration $C(x)$ at a depth $x$ is described by:

$$
C(x)=C_{0}\left[1-\operatorname{erf}\left(\frac{x}{2 \sqrt{D t}}\right)\right]
$$

where $\operatorname{erf}\left(\frac{x}{2 \sqrt{D t}}\right)$ is the error function [21], $D$ is the coefficient of deuterium migration and $t$ is the irradiation/exposure time. The concentration $C_{0}$ and the deuterium diffusivity are varied until the calculated profile matches the measured D profile in the bulk of the CFC material (Fig. 3). Note that the calculated proton yields for $\mathrm{D}$ depth profiles with tails approximated by the error functions are fitted well to the measured proton yields.

According to our fitting, the coefficients of D migration in the carbon fibre composites NB31 and N11 is barely dependent on the irradiation/exposure temperature and lies in the value interval between $5 \times 10^{-15}$ and $5 \times 10^{-17} \mathrm{~m}^{2} \mathrm{~s}^{-1}$ (Fig. 4).

Earlier, hydrogen diffusivity and Sieverts' constant in three-dimensional carbon fibre composites NB11 (SEP) and N11 (SEP) were determined by Sedano et al. [22, 23] with the use of a non-stationary model developed for iso-volumetric desorption experiments. In these experiments the apparent transport constants were derived. However, the fitting of the experimental hydrogen release using the homogeneous model was unsatisfactory, in that the experimental curve showed two overlapping time constants. The analysis of the hydrogen paths served to build a non-homogeneous diffusive model including diffusion in the composite matrix and fibre that fitted accurately the experimental release. Values for the hydrogen diffusivity in the matrix were found to be 6-7 orders of magnitude higher than in the fibres (Fig. 4). Sedano et al. [22, 23] suggested that the same processes govern the hydrogen diffusion in the bulk of both carbon subsystems.

Values for the deuterium migration derived from the D depth profiles are in good agreement with data for intrinsic hydrogen diffusivity in the fibres (Fig. 4). Note that the derived migration coefficients are practically not temperature dependent. Migration through 
pores along fibres with low activation energy may be considered as mechanism of deuterium penetration into the bulk of the CFC materials.

Apparently, the density of deuterium trap sites in the bulk of the fibres must be assumed to be significantly higher than that in the bulk of the matrix, such that the deuterium concentration in the bulk of the CFC materials represents trapping in the fibers. Note that the D depth profiles show no evidence that deuterium migrates into the CFC matrix through "fast channel” (Figs. 2 and 3). However, the concentration of deuterium retained at traps in the CFC matrix is thought to be below the detection limit of NRA. Thus, the very fast diffusion in the matrix and $\mathrm{D}$ trapping at larger depths may be responsible for the significantly larger retention obtained from TDS compared to the integration of depth profiles [24].

\section{Tungsten}

Three kinds of $\mathrm{W}$ materials were investigated:

(i) Single crystal tungsten (99.9 at.\% purity) produced by double electron-beam zone melting. The macro-crystallite sizes were in the range of 10-20 mm. The specimens were cut from a W rod by spark cutting and were 0.8-0.9 mm thick. The sample surface was parallel to the (100) crystallographic plane.

(ii) High purity (99.6 at.\%) polycrystalline tungsten foils, 0.3-0.4 mm thick, produced by Plansee AG (Reutte, Austria), a reduced-rolled, powder-metallurgy. The grain sizes were 2-20 $\mu \mathrm{m}$ (coarse-grained $\mathrm{W}$ ). This is the reference material for ITER.

(iii) A hot-rolled polycrystalline tungsten foil of 99.0 at.\% purity, $0.5 \mathrm{~mm}$ thick, manufactured in Russia, powder-metallurgy product. The grain sizes were 1-5 $\mu$ m (finegrained $\mathrm{W})$.

The W samples were mechanically and electrochemically polished. After polishing the single-crystalline samples and polycrystalline samples from Plansee were annealed at $1573 \mathrm{~K}$ for $3.5 \mathrm{~h}$ in a vacuum chamber with a background pressure of $\sim 2 \times 10^{-4} \mathrm{~Pa}$ during annealing.

\subsection{Irradiation with low flux D ions}

The retention of deuterium in tungsten develops differently at different depths. The depth at which deuterium is retained in the $\mathrm{W}$ materials irradiated with 200-1500 eV D ions can be conditionally divided into three zones: (i) the near-surface layer (up to a depth of 0.2-0.5 $\mu \mathrm{m}$, depending on the ion energy), (ii) a sub-surface layer (from about 0.5 to about $3 \mu \mathrm{m}$ ), and (iii) the bulk (> $6 \mu \mathrm{m})$ (Fig. 5). 
In $\mathrm{W}$ single crystals irradiated with $200 \mathrm{eV} \mathrm{D}$ ions at $323 \mathrm{~K}$, an increase of the ion fluence from $5 \times 10^{22}$ to $5 \times 10^{23} \mathrm{D} / \mathrm{m}^{2}$ leads to an increase of the near-surface concentration ${ }^{\text {near }} C_{\mathrm{D}}$ by a factor of more than 100 , from 0.01 to about 5 at.\% (Fig. 5 a). The drastic increase of the $\mathrm{D}$ concentration can only be explained by a sudden structural change during the lowenergy D ion irradiation, providing traps for D retention. The concentration within the subsurface layer is about 0.01 at.\% for all ion fluences used (Fig. 5 a), whereas the D concentration in the bulk (at depths beyond $6 \mu \mathrm{m}$ ) is below $10^{-3}$ at.\%.

In polycrystalline coarse-grained $\mathrm{W}$, the $\mathrm{D}$ concentration in the near-surface layer is in the range from 1 to 5 at.\% for fluences increasing from $1 \times 10^{23}$ to $8.9 \times 10^{24} \mathrm{D} / \mathrm{m}^{2}$ (Fig. $5 \mathrm{~b}$ ). Within the sub-surface layer, as the fluence is increased to $1 \times 10^{24} \mathrm{D} / \mathrm{m}^{2}$, the $\mathrm{D}$ concentration ${ }^{\text {sub }} C_{\mathrm{D}}$ reaches its maximum value of 0.1 at.\%. A further fluence increase leads to a decrease in the D concentration, and at high ion fluences $\left(\geq 3.2 \times 10^{24} \mathrm{D} / \mathrm{m}^{2}\right)$ the value ${ }^{\text {sub }} C_{\mathrm{D}}$ is $\sim 0.03$ at. The $\mathrm{D}$ concentration in the bulk increases with the ion fluence and reaches a steady state value of about $3 \times 10^{-3}$ at. $\%$ at a fluence of $1 \times 10^{24} \mathrm{D} / \mathrm{m}^{2}$ (Fig. $5 \mathrm{~b}$ ).

The release of deuterium from the sub-surface layer of polycrystalline $\mathrm{W}$ may be connected with the appearance of blisters and flaking and accompanying porosity development (Fig. 6). Note that blisters were not observed on $\mathrm{W}$ single crystal surfaces irradiated with $200 \mathrm{eV} \mathrm{D}$ ions, and the D concentration did not show a release of deuterium with increasing fluence.

The dependence of the $\mathrm{D}$ concentration on the temperature of post-irradiation annealing can provide information about nature of traps which are responsible for capture of deuterium. Changes of $\mathrm{D}$ depth profile in the polycrystalline coarse-grained $\mathrm{W}$ irradiated at $388 \mathrm{~K}$ with $1500 \mathrm{eV} \mathrm{D}$ ions to a fluence of $5 \times 10^{23} \mathrm{D} / \mathrm{m}^{2}$ caused by isochronous annealing (for $10 \mathrm{~min}$ ) are shown in Fig. 7.

It is evident that there are two ranges of the annealing temperatures at which the $\mathrm{D}$ concentration in $\mathrm{W}$ is reduced: $400-500 \mathrm{~K}$ and above $680-750 \mathrm{~K}$. According to van Veen et al. [25], the $D_{2}$ gas inside the voids is expected to be released during annealing at 400-600 K (detrapping energy $\sim 1.0 \mathrm{eV}$ ), whereas the $\mathrm{D}$ atoms bound on the inner surface of voids (binding energy $\sim 1.7 \mathrm{eV}$ ) is expected to be released at 700-900 K.

From these results the following retention behaviour can be deduced: For polycrystalline $\mathrm{W}$ irradiated with $200 \mathrm{eV}$ D ions, changes in the D concentration at high ion fluences result from $\mathrm{W}$ structure modifications caused by the low energy ion irradiation. As the ion fluence increases, the concentration of gas-filled voids within the sub-surface polycrystalline layer $(1-5 \mu \mathrm{m})$ increases, and interconnected porosity starts to develop. This leads to the release of a fraction of the molecular deuterium and is demonstrated by the 
decrease of the $\mathrm{D}$ concentration at $\Phi>1 \times 10^{24} \mathrm{D} / \mathrm{m}^{2}$ (Fig. $5 \mathrm{~b}$ ). In the bulk (at depths above 6 $\mu \mathrm{m}) \mathrm{D}$ atoms are thought to be chemisorbed on the inner walls of voids present initially in the polycrystalline $\mathrm{W}$ samples. The decrease of the $\mathrm{D}$ concentration starting at the annealing temperature of $700 \mathrm{~K}$ supports this assumption.

\subsection{Exposure to low-energy and high-flux D plasma}

In the single-crystalline and polycrystalline fine-grained $\mathrm{W}$ materials exposed to a lowenergy ( $\approx 200 \mathrm{eV} / \mathrm{D}$ ) and high-flux (about $1 \times 10^{21} \mathrm{D} / \mathrm{m}^{2} \mathrm{~s}$ ) magnetron $\mathrm{D}$ plasma at exposure temperatures of $T_{\exp }=303-313 \mathrm{~K}$, the $\mathrm{D}$ depth profile is characterized by a sharp near-surface concentration maximum (about 1 at.\%) and a decreasing concentration tail into the bulk (Fig. 8). At $T_{\exp }=413-493 \mathrm{~K}$, the $\mathrm{D}$ profile demonstrates, in addition to the near-surface peak, a relatively high D concentration (0.3-0.4 at.\%) in the sub-surface layer. The main difference between single-crystalline and polycrystalline fine-grained $\mathrm{W}$ materials is the constant concentration level in the bulk for polycrystalline material which is absent in single crystals.

Interesting is the comparison of implantation in single crystals with low and high ion fluxes (Figs. 5 a and 8 a) at room temperature. While at low ion flux D diffuses into the bulk reaching concentrations of $5 \times 10^{-3}$ at.\% at a depth of $6 \mu \mathrm{m}$, at high ion fluxes high surface concentrations build up leading to an enhanced D release through the surface and the inward concentration profile decreases below the sensitivity of the measurements at a depth of 1.5 $\mu \mathrm{m}$. Evidently, the depth of the D trapping depends on the exposure time.

The concentration of $\mathrm{D}_{2}$ molecules (in arbitrary units) within the near-surface layer of the $\mathrm{W}$ crystal was determined by measuring the $\mathrm{D}_{2}$ release rate in the course of surface sputtering with Ar ions (RGA measurement). A characteristic of the $\mathrm{D}_{2}$ release rate after exposure to the $\mathrm{D}$ plasma at $T_{\exp }=373 \mathrm{~K}$ is that the repetitive $\mathrm{D}_{2}$ gas bursts occur throughout the whole analysis time corresponding to a depth of $\sim 450 \mathrm{~nm}$ (Fig. 9). The appearance of $\mathrm{D}_{2}$ molecules is related to the formation of voids filled by gaseous deuterium. Based on the D depth profiles (Fig. 8), one may assume the void formation at depths at least up to 1-2 $\mu \mathrm{m}$.

After exposure to the D plasma at elevated temperatures blisters are formed on the surfaces both of the $\mathrm{W}$ single crystal and polycrystalline $\mathrm{W}$. For the $\mathrm{W}$ single crystal exposed at $T_{\text {exp }}$ in the range from 373 to $533 \mathrm{~K}$ the mean size (diameter) of blisters is $3-5 \mu \mathrm{m}$ and does not depend on the exposure temperature. The maximum areal density of blisters is observed at $T_{\exp }=413-463 \mathrm{~K}$, whereas at $T_{\exp }=533 \mathrm{~K}$ only solitary blisters are present on the surface of the $\mathrm{W}$ single crystal. For the polycrystalline $\mathrm{W}$ the mean blister size is about $3 \mu \mathrm{m}$ at $T_{\exp }=$ $313 \mathrm{~K}$ and grows to the maximum value of about $30 \mu \mathrm{m}$ at $T_{\exp }=573 \mathrm{~K}$. Cracks are observed 
on the surface of blister lids and the release of $\mathrm{D}_{2}$ molecules becomes evident from the concentration minimum of the $\mathrm{D}$ depth profile between the near-surface and sub-surface maxima. At exposure temperatures above $650 \mathrm{~K}$ blisters are not formed on the surface of the polycrystalline $\mathrm{W}$.

In the $\mathrm{W}$ single crystal exposed to the $\mathrm{D}$ plasma, the deuterium retention is about $1.3 \times 10^{20} \mathrm{D} / \mathrm{m}^{2}$ at $T_{\exp }=303 \mathrm{~K}$ and, as exposure temperature further increases, rises to its maximum of about $4.3 \times 10^{20} \mathrm{D} / \mathrm{m}^{2}$ at $T_{\exp }=463 \mathrm{~K}$ and then decreases down to about $1.6 \times 10^{19}$ $\mathrm{D} / \mathrm{m}^{2}$ at $T_{\exp }=533 \mathrm{~K}$ (Fig. $10 \mathrm{a}$ ). In the polycrystalline fine-grained $\mathrm{W}$, the $\mathrm{D}$ retention demonstrates practically the same temperature dependence as that in the $\mathrm{W}$ single crystal, but the maximum retention in the polycrystalline $\mathrm{W}$ is about $4.9 \times 10^{20} \mathrm{D} / \mathrm{m}^{2}$ at $T_{\exp }=493 \mathrm{~K}$ (Fig. 10 a).

In the polycrystalline coarse-grained W irradiated with $200 \mathrm{eV}$ D ions at low flux (about $4 \times 10^{19} \mathrm{D} / \mathrm{m}^{2} \mathrm{~s}$ ), the $\mathrm{D}$ retention decreases drastically as the irradiation temperature increases from 323 to $393 \mathrm{~K}$ (Fig. 10 a). Obviously, D retention with a maximum at higher temperature is observed when the $\mathrm{W}$ materials are exposed to high flux D plasma. Data on the D retention in polycrystalline $\mathrm{W}$ exposed to low-energy (about $100 \mathrm{eV} / \mathrm{D}$ ) and high flux (about $1 \times 10^{22} \mathrm{~m}^{-}$ ${ }^{2} \mathrm{~s}^{-1}$ ) hydrogen isotope plasmas taken from Refs. [9-12] are shown in Fig. 10 b. As seen from the figure, for the ion fluxes of about $1 \times 10^{22} \mathrm{~m}^{-2} \mathrm{~s}^{-1}$ a drastic decrease in the $\mathrm{D}$ retention is observed at the exposure temperatures above 650-700 K. In our experiments with the ion flux of about $1 \times 10^{21} \mathrm{~m}^{-2} \mathrm{~s}^{-1}$, the decreasing in the $\mathrm{D}$ retention begins at about $500 \mathrm{~K}$. Evidently, the ion flux affects not only the D retention in W materials, as it was reported in [10,14], but also the temperature where the $\mathrm{D}$ retention reaches its maximum.

The high deuterium concentration in the sub-surface layer and the formation of blisters allows the conclusion that irradiation with $200 \mathrm{eV} \mathrm{D}$ ions and exposure to the D plasma modify the surface to depths of up to $2-4 \mu \mathrm{m}$, both for $\mathrm{W}$ single crystals and polycrystalline W. These depths are much larger than the deuterium implantation range. The sputter-RGA measurements show that a part of deuterium is accumulated in the form of $\mathrm{D}_{2}$ molecules in the near-surface layer. It could be supposed that $\mathrm{D}_{2}$ molecules (or rather $\mathrm{D}_{2}$-filled voids) are formed in the sub-surface layer also (up to depths of several micrometers). The decrease of the $\mathrm{D}$ concentration at a depth of $1 \mu \mathrm{m}$ in polycrystalline $\mathrm{W}$ at annealing temperatures of 423$523 \mathrm{~K}$ (Fig. 7) favours the assumption that most of the deuterium retained within the subsurface layer is accumulated in the form of $\mathrm{D}_{2}$ molecules. However, the energy of the $\mathrm{D}$ ions of $200 \mathrm{eV}$ is below the energy threshold for displacement of $\mathrm{W}$ atoms of above $800 \mathrm{eV}$. A review of hydrogen bubbles in metals by Condon and Schober [26] outlines some possible void formation mechanisms. The mechanism of near-surface plastic deformation caused by the deuterium supersaturation within the near-surface layer was considered by Poon [27] for 
the explanation of TDS spectra for W single crystals. This mechanism is also proposed for the interpretation of the present results. During D ion irradiation or D plasma exposure the D concentration in the implantation zone greatly exceeds the solubility limit and stresses the matrix lattice until plastic deformation with formation of voids and vacancy clusters occurs to alleviate these tensions. This deformation is assumed to be responsible for the sudden increase in trapping sites for deuterium and the concurrent accumulation of deuterium, both in the form of $\mathrm{D}_{2}$ molecules and $\mathrm{D}$ atoms. Traces of the plastic deformation within the sub-surface layer of the W single crystal are observed as etching pits oriented along certain crystallographic plane. These etching pits are created due to preferential sputtering of dislocation lines intersecting the surface. According to Savitsky and Burkhanov [28], at plastic deformations of $6-10 \%$ the dislocation lines in the bcc lattice are parallel to the direction of the closest packing. But at higher degree of the deformation, a texture is formed.

After irradiation with $200 \mathrm{eV}$ D ions at a low flux of about $4 \times 10^{19} \mathrm{D} / \mathrm{m}^{2} \mathrm{~s}$, the maximum concentration of $\mathrm{D}_{2}$ molecules at depths of $1-3 \mu \mathrm{m}$ in the polycrystalline $\mathrm{W}$ specimen is at least one order of magnitude higher than that in the W single crystals (Fig. 5). Thus, the initial structure of the $\mathrm{W}$ materials plays a major role in the stress-induced void formation. Possibly, the grain boundaries serve as preferential sites for void nucleation and growth. However, after exposure to the high-flux (about $10^{21} \mathrm{D} / \mathrm{m}^{2} \mathrm{~s}$ ) $\mathrm{D}$ plasma, the maximum $\mathrm{D}$ concentration in the sub-surface layer (at depths of 1-3 $\mu \mathrm{m}$ ) is $0.3-0.4$ at.\% both in the $\mathrm{W}$ single crystal and polycrystalline W (Fig. 8). Apparently, for high-flux D ion implantation formation of the stress-induced defect depends on the $\mathrm{W}$ structure to lesser degree than that for low-flux implantation.

\section{Comparison under fusion applications}

For comparison the retention of carbon (pyrolytic graphite and CFC), tungsten (polycrystalline material and plasma-sprayed coatings [29]) are presented in Fig. 11. The comparison is done for irradiation with $200 \mathrm{eV} \mathrm{D}^{+}$at room temperature, although in ITER the surface temperatures will range around $200^{\circ} \mathrm{C}$. For comparison, data for Be are also included in Fig. 11 from Ref. [1] and recent measurements with ion beams [30]. For the different applications of the materials in ITER (CFC strike point tiles, W divertor baffle and Be first wall) the expected incident fluences for one ITER discharge is indicated .

The use of CFC as strike point tiles (with total surface area of $10 \mathrm{~m}^{2}$ ) will lead to the largest tritium inventory after one discharge. Not only does CFC retain the highest levels of hydrogen, co-deposition of hydrogen with eroded carbon exceeds these levels by far already after less than 100 discharges [31]. Retained levels of deuterium in $\mathrm{W}$ are not negligible due 
to the much larger total $\mathrm{W}$ surface area (about $100 \mathrm{~m}^{2}$ ) and the possible application of plasmasprayed coatings. Co-deposition with $\mathrm{W}$ is not expected [32]. In Be, the retained hydrogen amount saturates within the first discharge and no implanted inventory is being build up. However, the large total surface area of Be used (about $700 \mathrm{~m}^{2}$ ) leads to high erosion and subsequent co-deposition with hydrogen. The concentration of hydrogen in deposited Be layers depends critically on temperature and degree of contamination with carbon and oxygen impurities [33], such that the inventory due to co-deposition cannot be predicted today.

\section{Conclusions}

The structure of CFC, with the largely different materials of the fibres and matrix, with its layered fibre structure and large porosity between the layers allows hydrogen to penetrate much further than into graphite. While in graphite quasi-saturation on the retention occurs, the retention in CFC increases continuously with ion fluence in the data range available.

Retention in W irradiated with low-energy D ions depends strongly on the material structure. The depth at which deuterium is retained can be divided into three zones: (i) the near-surface layer (up to a depth of 0.2-0.5 $\mu \mathrm{m}$ ), (ii) the sub-surface layer (from about 0.5 to about $3 \mu \mathrm{m}$ ), and (iii) the bulk (>6 $6 \mathrm{~m})$. The D concentration at high ion fluences $\left(\geq 1 \times 10^{24}\right.$ $\mathrm{D} / \mathrm{m}^{2}$ ) decreases from several at.\% in the near-surface layer to below $10^{-4}$ at.\% for $\mathrm{W}$ single crystal, $3 \times 10^{-3}$ at.\% for polycrystalline coarse-grained $\mathrm{W}$, and $3 \times 10^{-2}$ at.\% for polycrystalline fine-grained $\mathrm{W}$ in the bulk. With increasing fluence the retention increases monotonically roughly proportional to the square root of the fluence.

In the case of the D plasma exposure, the total deuterium retention in single-crystalline and polycrystalline $\mathrm{W}$ increases with the exposure temperature reaching its maximum value of $5 \times 10^{20} \mathrm{D} / \mathrm{m}^{2}$ at about $500 \mathrm{~K}$ and then decreases as the temperature grows further. The high D concentration (about 0.3 at.\%) at depths of $1-3 \mu \mathrm{m}$ is due to accumulation of $\mathrm{D}_{2}$ molecules in voids created during $\mathrm{D}$ plasma exposure.

D ion irradiation and D plasma exposure with ion energies well below the displacement threshold modifies the $\mathrm{W}$ structure to depths of up to about $5 \mu \mathrm{m}$, both in $\mathrm{W}$ single crystals and polycrystalline $\mathrm{W}$. Plastic deformation of the $\mathrm{W}$ surface caused by deuterium supersaturation within the near-surface layer is proposed as explanation of the present results.

The comparison of CFC, W and Be in ITER application shows that retention in carbon dominates the tritium inventory. At low ion fluences implantation into CFC dominates, while at high fluences, as reached in today's fusion devices within a typical experimental campaign, co-deposition with carbon exceeds implantation. In ITER co-deposition of tritium with carbon will form the largest inventory after less than 100 discharges. The retention in $\mathrm{W}$ depends on 
the structural properties of the material, due to very low erosion and low co-deposition $\mathrm{W}$ will not be a problem for the $\mathrm{T}$ inventory. For Be, more information is needed on the co-deposition properties and its dependence on contaminations in the deposited Be layers. 


\section{References}

[1] Anderl, R.A., Causey, R.A., Davis, J.W., Doerner, R.P., Federici, G., Haasz, A.A., Longhurst, G.R., Wampler, W.R. and Wilson, K.L., J. Nucl. Mater. 273, 1 (1999).

[2] Causey, R.A. and Venhaus, T.J., Physica Scripta T94, 9 (2001).

[3] Causey, R.A., J. Nucl. Mater. 300, 91 (2002).

[4] Emmoth, B., Rubel, M. and Franconi, E., Nucl. Fusion 30, 1140 (1990).

[5] Penzhorn, R.-D., Bekris, N., Berndt, U., Coad, J.P., Ziegler, H. and Nägele, W., J. Nucl. Mater. 288, 170 (2001).

[6] Penzhorn, R.-D., Coad, J.P., Bekris, N., Doerr, L., Friedrich, M. and Pilz, W., Fusion Eng. Des. 56\&57, 105 (2001).

[7] Bekris, N., Skinner, C.H., Berndt, U., Gentile, C.A., Glugla, M. and Schweigel, B., J. Nucl. Mater. 313-316, 501 (2003).

[8] Tadokoro, T., Isobe, K., O’hira, S., Shu, W. and Nishi, M., J. Nucl. Mater. 283-287, 1048 (2000).

[9] Causey, R., Wilson, K., Venhaus, T. and Wampler, W.R., J. Nucl. Mater. 266-269, 467 (1999).

[10] Venhaus, T., Causey, R., Doerner, R. and Abeln, T., J. Nucl. Mater. 290-293, 505 (2001).

[11] Tokunaga, K., Baldwin, M.J., Doerner, R.P., Noda, N., Kubota, Y., Yoshida, N., Sogabe, T., Kato, T. and Schedler, B., J. Nucl. Mater. 337-339, 887 (2005).

[12] Luo, G.-N., Shu, W.M. and Nishi, M., Fusion Eng. Des. 81, 957 (2006).

[13] Haasz, A.A., Davis, J.W., Poon, M. and Macaulay-Newcombe, R.G., J. Nucl. Mater. 258-263, 889 (1998).

[14] Poon, M., Macaulay-Newcombe, R.G., Davis, J.W. and Haasz, A.A., J. Nucl. Mater. 307-311 723 (2002).

[15] Poon, M., Haasz, A.A., Davis, J.W. and Macaulay-Newcombe, R.G., J. Nucl. Mater. 313-316, 199 (2003).

[16] Eckstein, W., García-Rosales, C., Roth, J. and Ottenberger, W., Sputtering Data, Tech. Rep. IPP 9/82, Max-Planck-Institut für Plasmaphysik, Garching, 1993.

[17] Alimov, V.Kh., Komarov, D.A., Roth, J., Mayer, M. and Lindig, S., J. Nucl. Mater. 349, 282 (2006).

[18] Goebel, D.M., Bohdansky, J., Conn, R.W., Hirooka, Y., LaBombard, B., Leung, W.K., Nygren, R.E., Roth, J. and Tynan, G.R., Nucl. Fusion, 28, 1041 (1988).

[19] Alimov, V.Kh., Mayer, M. and Roth, J., Nucl. Instr. and Meth. B 234, 169 (2005). 
[20] Staudenmaier, G., Roth, J., Behrisch, R., Bohdansky, J., Eckstein, W., Staib, P., Matteson, S. and Erents, S.K., J. Nucl. Mater. 84, 149 (1979).

[21] Crank, J., Mathematics of Diffusion (University Press, Oxford, 1956).

[22] Sedano, L.A., Alberici, S., Perujo, A., Camposilvan, J. and Douglas, K., J. Nucl. Mater. 258-263, 662 (1998).

[23] Sedano, L.A., Perujo, A. and Wu, Ch.H., J. Nucl. Mater. 273, 285 (1999).

[24] Roth, J., Alimov, V.Kh., Golubeva, A.V., Doerner, R.P., Hanna, J., Tsitrone, E., Brosset, Ch., Rohde, V., Herrmann, A. and Mayer, M., J. Nucl. Mater. (2006), accepted for publication.

[25] Van Veen, A., de Vries, J., Segers, D. and Rozing, G.J., in: Jain, P.C., Singru, R.M. and Gopinathan, K.P. (Eds.), Positron Annihilation, World Scientific Publ. Co., Singapore, 1985, p. 543.

[26] Condon, J.B. and Schober, T., J. Nucl. Mater. 207, 1 (1993).

[27] Poon, M., Deuterium Trapping in Tungsten, Ph. D. Thesis, Toronto University, 2004.

[28] Savitsky, E.M. and Burkhanov, G.S., Single Crystals of Refractory and Less-Common Metals and Alloys, Nauka, Moscow, 1972 (in Russian).

[29] Golubeva, A.V., Alimov, V.Kh. and Roth, J., Private communication, (2006).

[30] Alimov, V.Kh. and Roth, J., Private communication (2006).

[31] Roth, J. Kirschner, A., Bohmeyer, W., Brezinsek, S., Cambe, A., Casarotto, E., Doerner, R., Gauthier, E., Federici, G., Higashijima, S. et al., J. Nucl. Mater. 337-339, 970 (2005).

[32] Mayer, M., Behrisch, R., Plank, H., Roth, J., Dollinger, G. and Frey, C.M., J. Nucl. Mater. 230, 67 (1996).

[33] Baldwin, M.J., Schmid, K., Doerner, R.P., Wiltner, A., Seraydarian, R. and Linsmeier, Ch., J. Nucl. Mater. 337-339, 590 (2005). 


\section{Figure captures}

Fig. 1. Deuterium retention in carbon fibre composites NB31 and N11 compared to pyrolytic graphite as a function of incident ion fluence. CFC NB31 was irradiated with $200 \mathrm{eV}$ D ions, CFC N11 was exposed to $150 \mathrm{eV}$ D plasma in PISCES-A. Data for pyrolytic graphite are taken from Ref. [20]. The D retention was measured by thermal desorption spectrometry.

Fig. 2. Depth profiles of deuterium trapped in CFC NB31 and pyrolytic graphite HPG irradiated with $200 \mathrm{eV}$ D ions at $323 \mathrm{~K}$ to various fluences.

Fig. 3: Depth profiles of deuterium in CFC NB31 after implantation with $200 \mathrm{eV}$ D ions to a fluence of $5 \times 10^{24} \mathrm{D} / \mathrm{m}^{2}$ (a) and after exposure to a low-energy ( $\left.\approx 200 \mathrm{eV} / \mathrm{D}\right)$ and high ion flux (about $1 \times 10^{21} \mathrm{D} / \mathrm{m}^{2} \mathrm{~s}$ ) deuterium magnetron plasma to a fluence of about $2 \times 10^{24} \mathrm{D} / \mathrm{m}^{2}$ (b) at various temperatures. Solid lines represent depth profiles calculated with the use of onedimensional diffusion equation (1).

Fig. 4. Coefficients of deuterium migration in CFC NB31 and N11, as derived from the D depth profiles with the use of the one-dimensional diffusion equation (1), and values for hydrogen diffusivity in CFC subsystems (matrix and fibres) for CFC NB11 and N11 [22, 23].

Fig. 5. Depth profiles of deuterium trapped in W single crystal (a) and polycrystalline coarsegrained W (b) irradiated at 300-323 K with $200 \mathrm{eV}$ D ions to various fluences.

Fig. 6. SEM image of polycrystalline coarse-grained W surface irradiated with $200 \mathrm{eV}$ D ions at $323 \mathrm{~K}$ to a fluence of $8.9 \times 10^{24} \mathrm{D} / \mathrm{m}^{2}$.

Fig. 7. Depth profiles of deuterium trapped in polycrystalline coarse-grained $\mathrm{W}$ irradiated with $1500 \mathrm{eV} \mathrm{D}$ ions at $388 \mathrm{~K}$ to a fluence of $5 \times 10^{23} \mathrm{D} / \mathrm{m}^{2}$ and then annealed at fixed temperature for $10 \mathrm{~min}$.

Fig. 8. Depth profiles of deuterium trapped in W single crystal (a) and polycrystalline finegrained W (b) exposed to a low-energy $(\approx 200 \mathrm{eV} / \mathrm{D})$ and high-flux $\left(\approx 10^{21} \mathrm{~m}^{-2} \mathrm{~s}^{-1}\right)$ deuterium plasma to a fluence of about $2 \times 10^{24} \mathrm{D} / \mathrm{m}^{2}$ at various temperatures. 
Fig. 9. Depth profile of deuterium in W single crystal exposed to a low-energy ( $\approx 200 \mathrm{eV} / \mathrm{D})$ and high ion flux $\left(\approx 10^{21} \mathrm{~m}^{-2} \mathrm{~s}^{-1}\right)$ D plasma to a fluence of about $2 \times 10^{24} \mathrm{D} / \mathrm{m}^{2}$ at $373 \mathrm{~K}$ as measured with the $\mathrm{D}\left({ }^{3} \mathrm{He}, \alpha\right) \mathrm{H}$ nuclear reaction (NRA) and with the sputter-residual gas analysis technique (RGA). Note that the concentration of $\mathrm{D}_{2}$ molecules (RGA measurement) is given in arbitrary units.

Fig. 10. a) Deuterium retention in single-crystalline and polycrystalline fine-grained tungsten exposed to the low-energy ( $\approx 200 \mathrm{eV} / \mathrm{D}$ ) and high flux (about $1 \times 10^{21} \mathrm{D} / \mathrm{m}^{2} \mathrm{~s}$ ) D plasma as a function of the exposure temperature. For comparison, the temperature dependence of the D retention in polycrystalline coarse-grained W irradiated with $200 \mathrm{eV} \mathrm{D}$ ions and flux of $4 \times 10^{19} \mathrm{D} / \mathrm{m}^{2} \mathrm{~s}$ to a fluence of $1 \times 10^{24} \mathrm{D} / \mathrm{m}^{2}$ is also shown. Note the deuterium retention was calculated from deuterium depth profiles measured up to a depth of $7 \mu \mathrm{m}$.

b) Deuterium retention in polycrystalline tungsten exposed to low-energy (98-100 eV/D(T)) and high flux $\left((8.7-10) \times 10^{21} \mathrm{D}(\mathrm{T}) / \mathrm{m}^{2} \mathrm{~s}\right) \mathrm{D}$ or $(\mathrm{D}+\mathrm{T})$ plasmas as a function of the exposure temperature. Data are taken from Ref. [9-12]. The deuterium retention was examined by TDS.

Fig. 11. Deuterium retention in carbon (pyrolytic graphite and CFC materials), polycrystalline and vacuum plasma sprayed (VPS) tungsten, and beryllium irradiated with $200 \mathrm{eV}$ D ions at room temperature as a function of incident ion fluence. The data for Be are taken from Ref. [1] and from recent measurements [30]. Arrows indicate expected D/T ion fluences incident on the surfaces of Be, CFC and W materials, respectively, during one ITER discharge. 


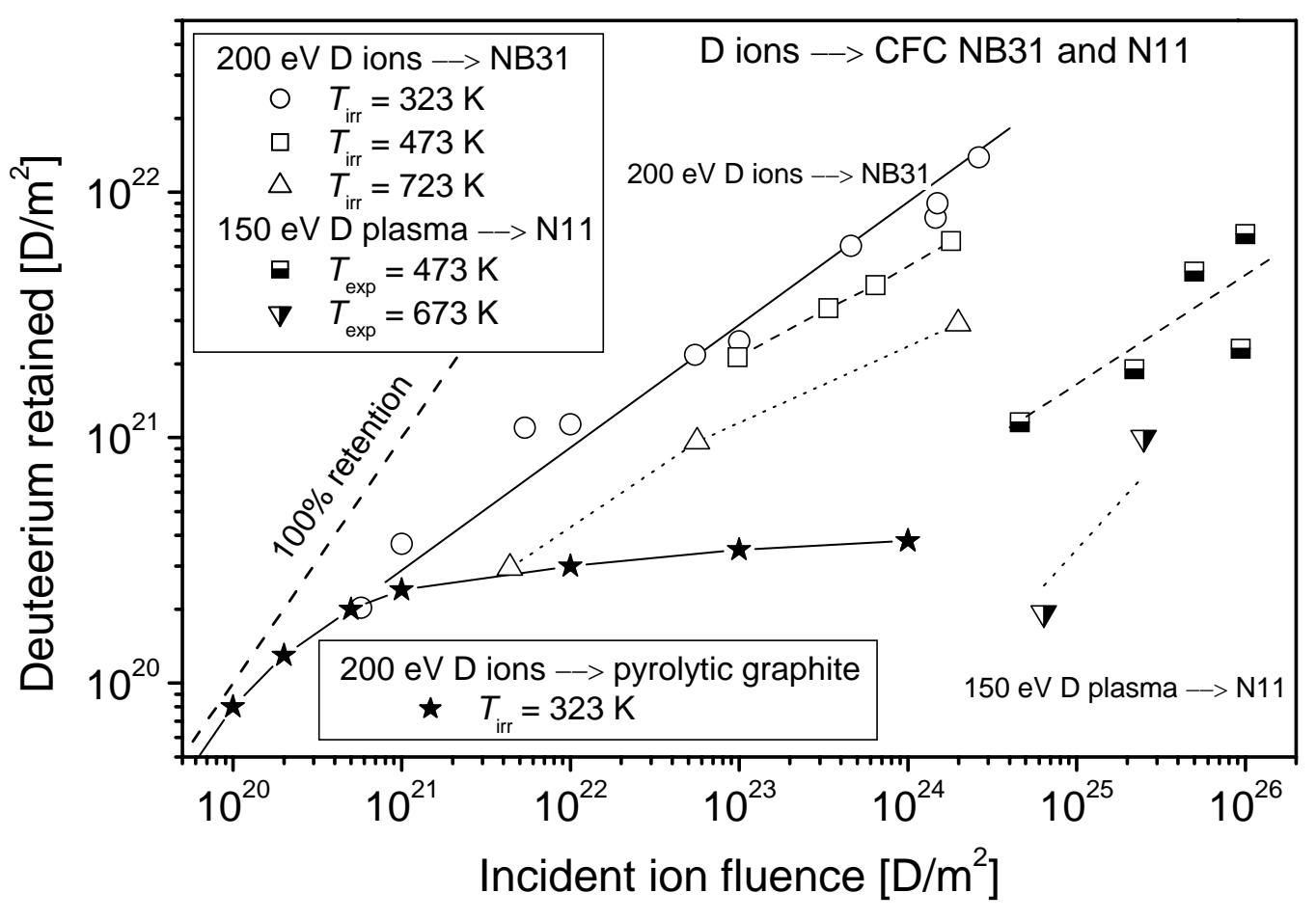

Fig. 1. Deuterium retention in carbon fibre composites NB31 and N11 compared to pyrolytic graphite as a function of incident ion fluence. CFC NB31 was irradiated with $200 \mathrm{eV}$ D ions, CFC N11 was exposed to $150 \mathrm{eV}$ D plasma in PISCES-A. Data for pyrolytic graphite are taken from Ref. [20]. The D retention was measured by thermal desorption spectrometry. 


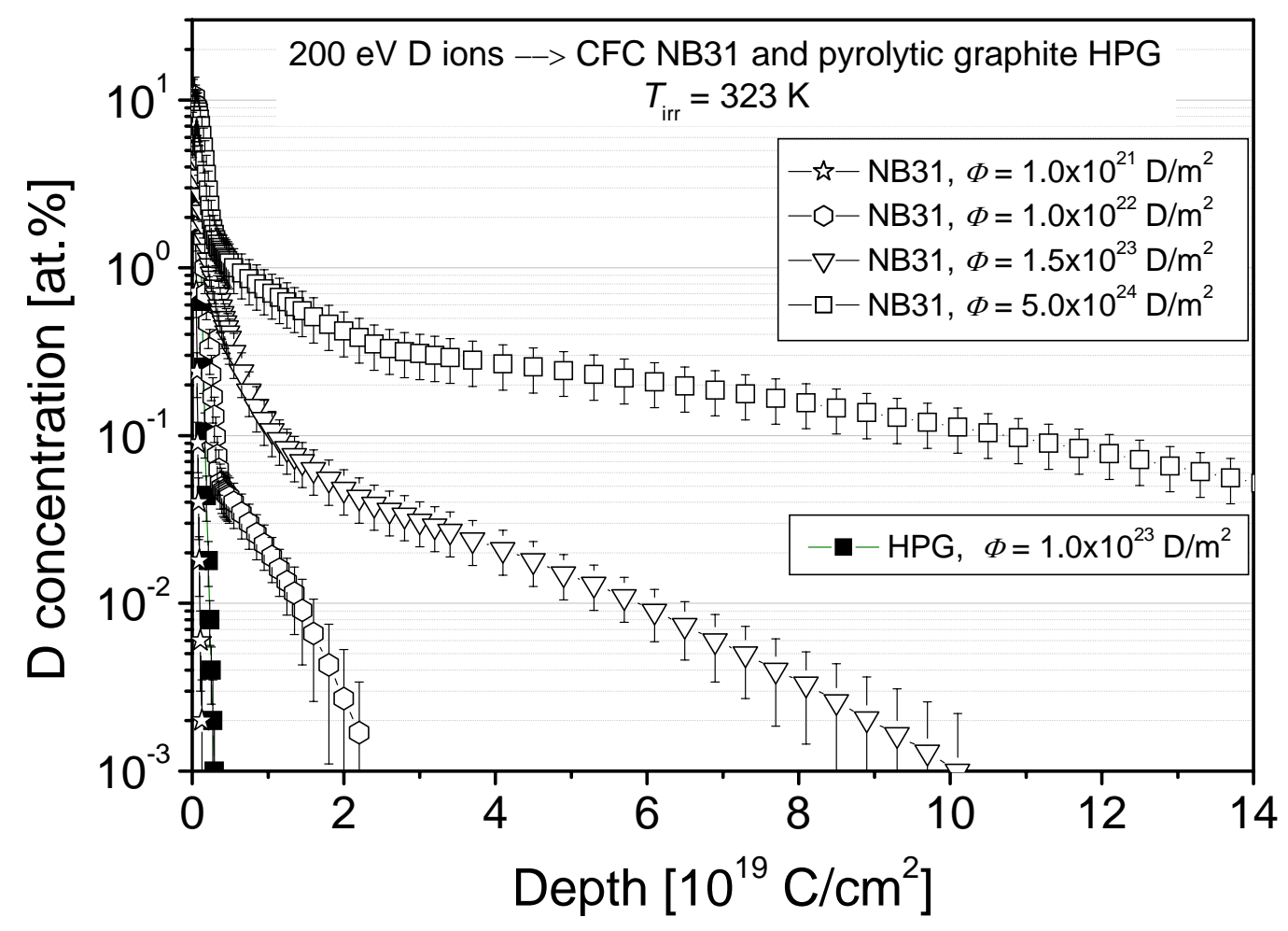

Fig. 2. Depth profiles of deuterium trapped in CFC NB31 and pyrolytic graphite HPG irradiated with $200 \mathrm{eV}$ D ions at $323 \mathrm{~K}$ to various fluences. 


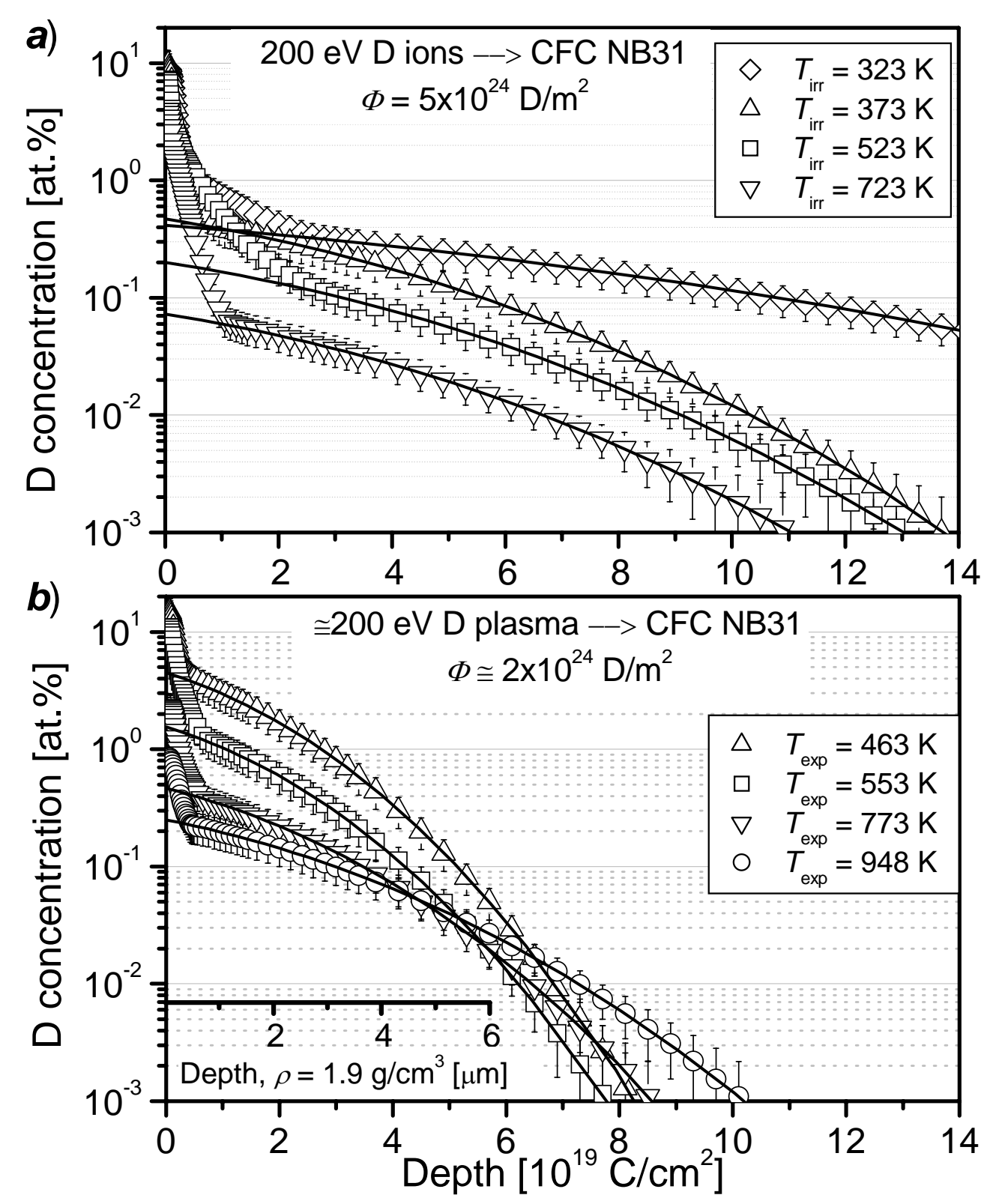

Fig. 3. Depth profiles of deuterium in CFC NB31 after implantation with $200 \mathrm{eV}$ D ions to a fluence of $5 \times 10^{24} \mathrm{D} / \mathrm{m}^{2}$ (a) and after exposure to a low-energy ( $\left.\approx 200 \mathrm{eV} / \mathrm{D}\right)$ and high ion flux (about $1 \times 10^{21} \mathrm{D} / \mathrm{m}^{2} \mathrm{~s}$ ) deuterium magnetron plasma to a fluence of about $2 \times 10^{24} \mathrm{D} / \mathrm{m}^{2}$ (b) at various temperatures. Solid lines represent depth profiles calculated with the use of onedimensional diffusion equation (1). 


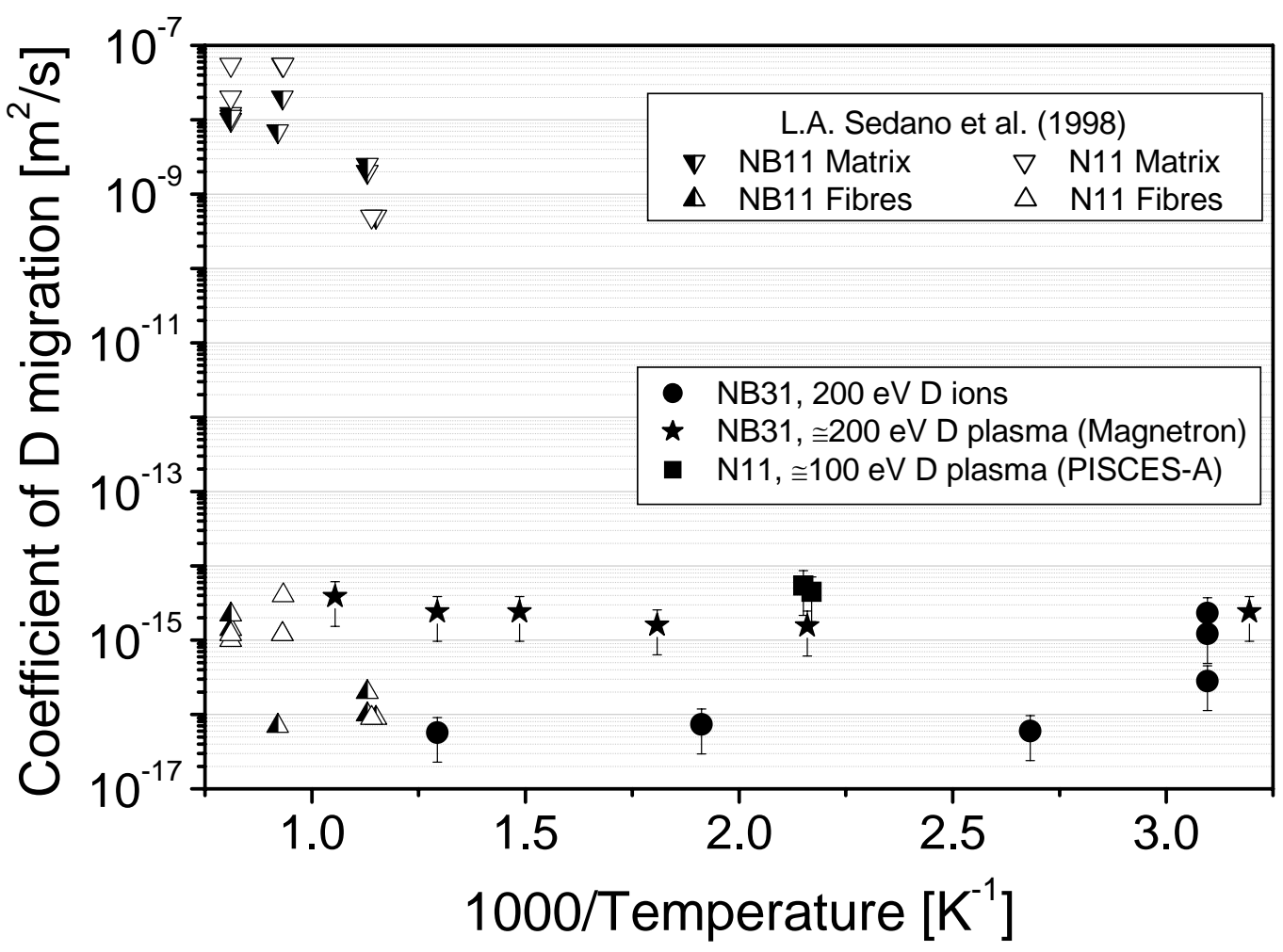

Fig. 4. Coefficients of deuterium migration in CFC NB31 and N11, as derived from the D depth profiles with the use of the one-dimensional diffusion equation (1), and values for hydrogen diffusivity in CFC subsystems (matrix and fibres) for CFC NB11 and N11 [22, 23]. 

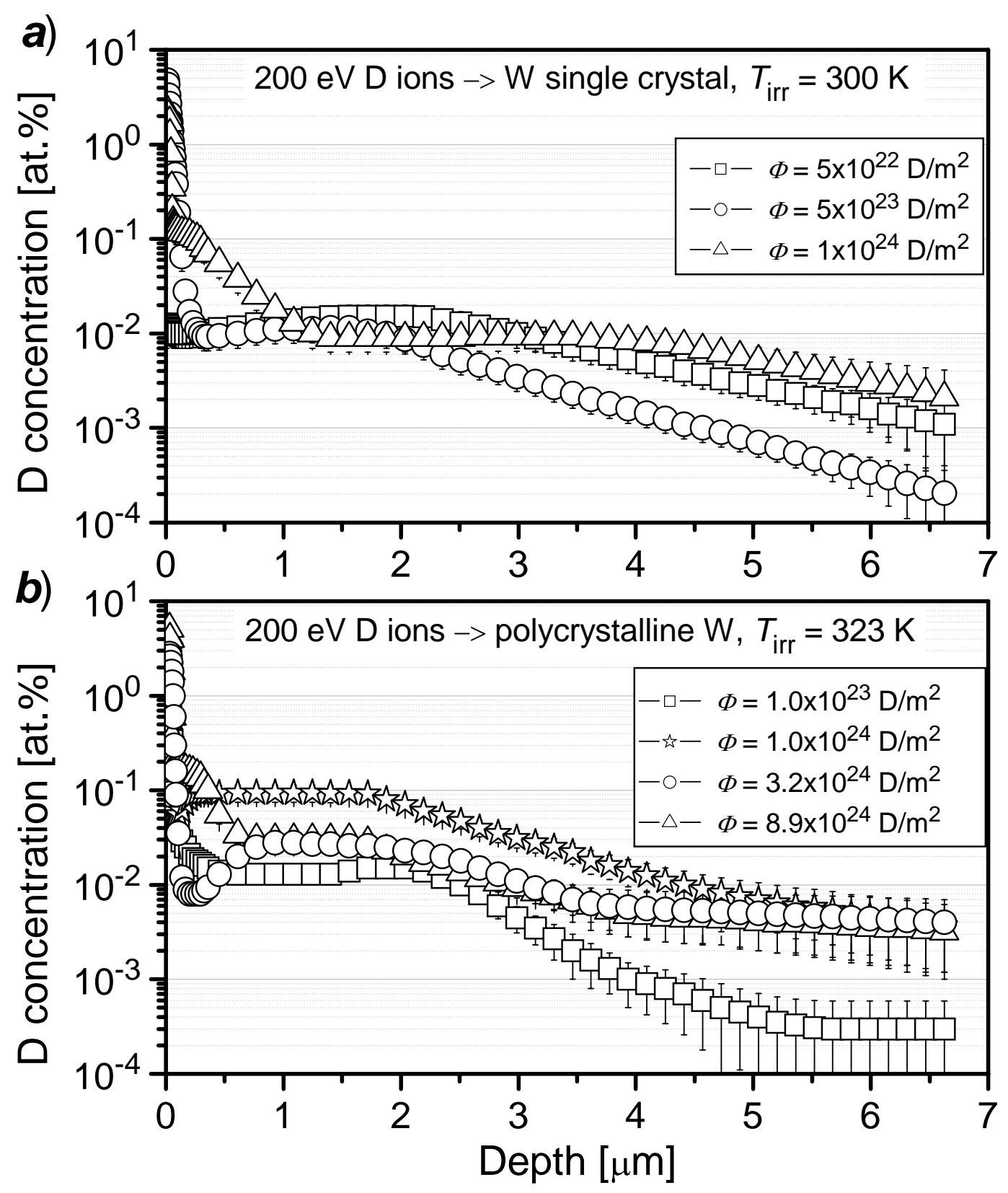

Fig. 5. Depth profiles of deuterium trapped in W single crystal (a) and polycrystalline coarsegrained W (b) irradiated at 300-323 K with $200 \mathrm{eV}$ D ions to various fluences. 


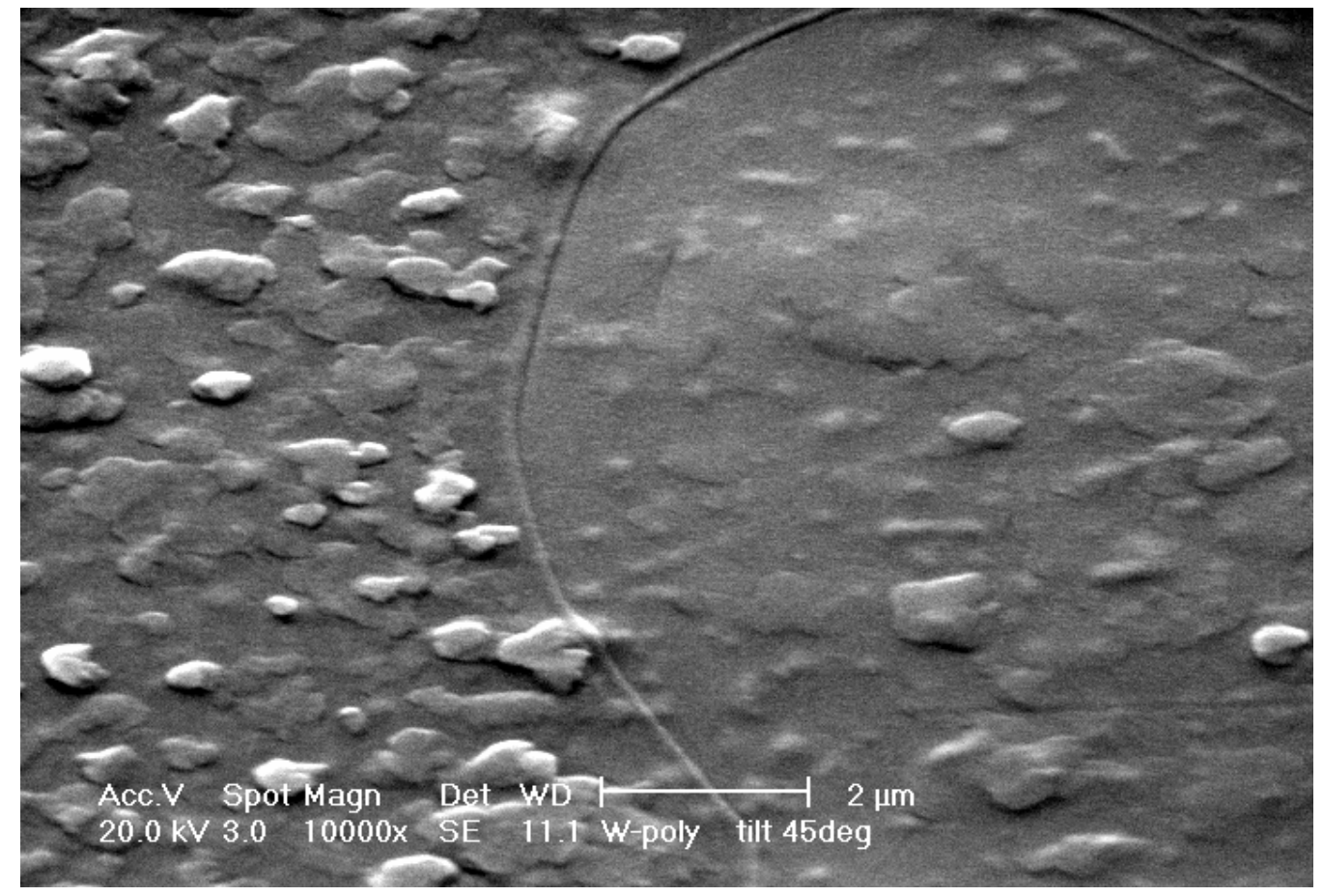

Fig. 6. SEM image of polycrystalline coarse-grained W surface irradiated with $200 \mathrm{eV}$ D ions at $323 \mathrm{~K}$ to a fluence of $8.9 \times 10^{24} \mathrm{D} / \mathrm{m}^{2}$. 


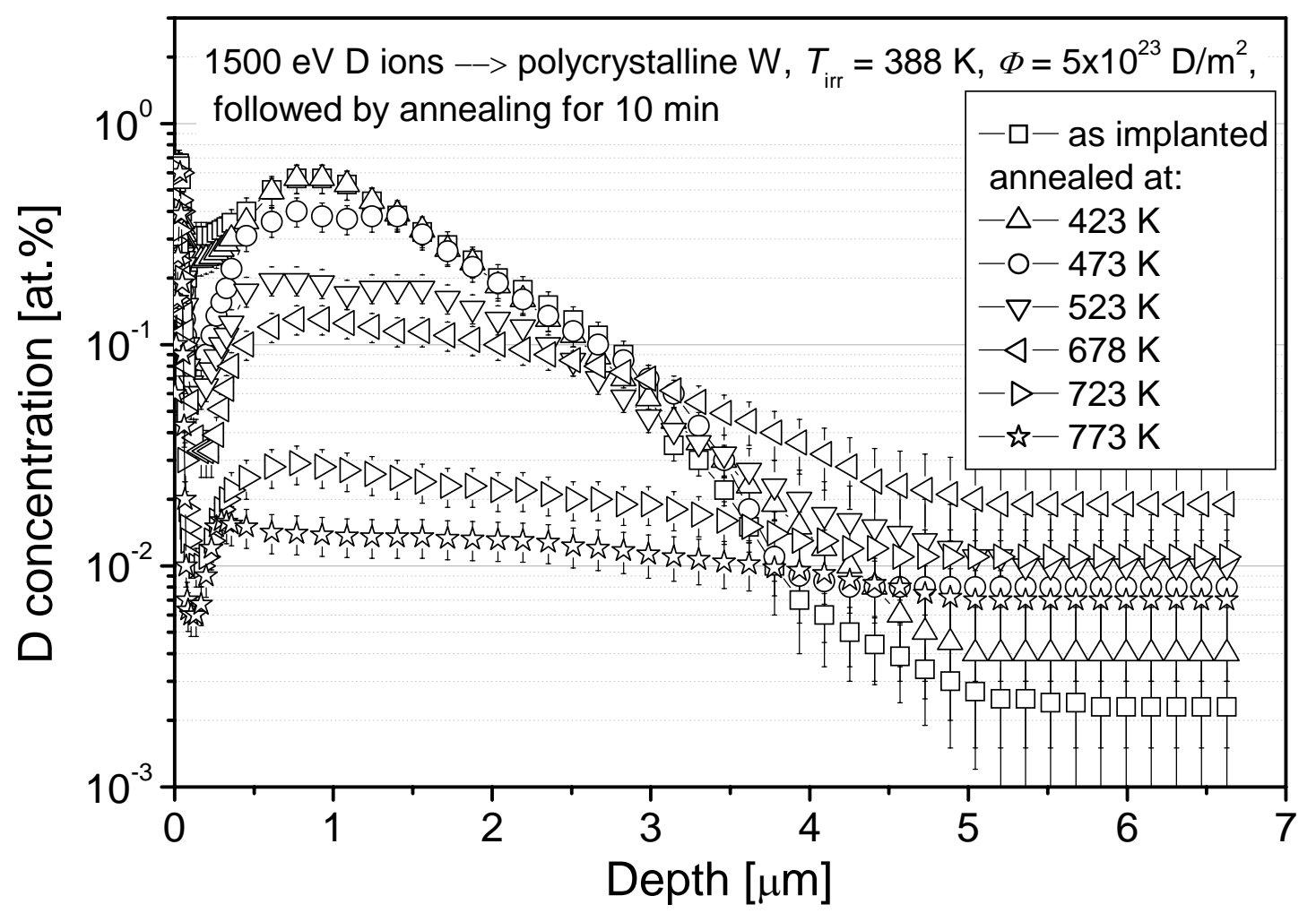

Fig. 7. Depth profiles of deuterium trapped in polycrystalline coarse-grained $\mathrm{W}$ irradiated with $1500 \mathrm{eV} \mathrm{D}$ ions at $388 \mathrm{~K}$ to a fluence of $5 \times 10^{23} \mathrm{D} / \mathrm{m}^{2}$ and then annealed at fixed temperature for $10 \mathrm{~min}$. 

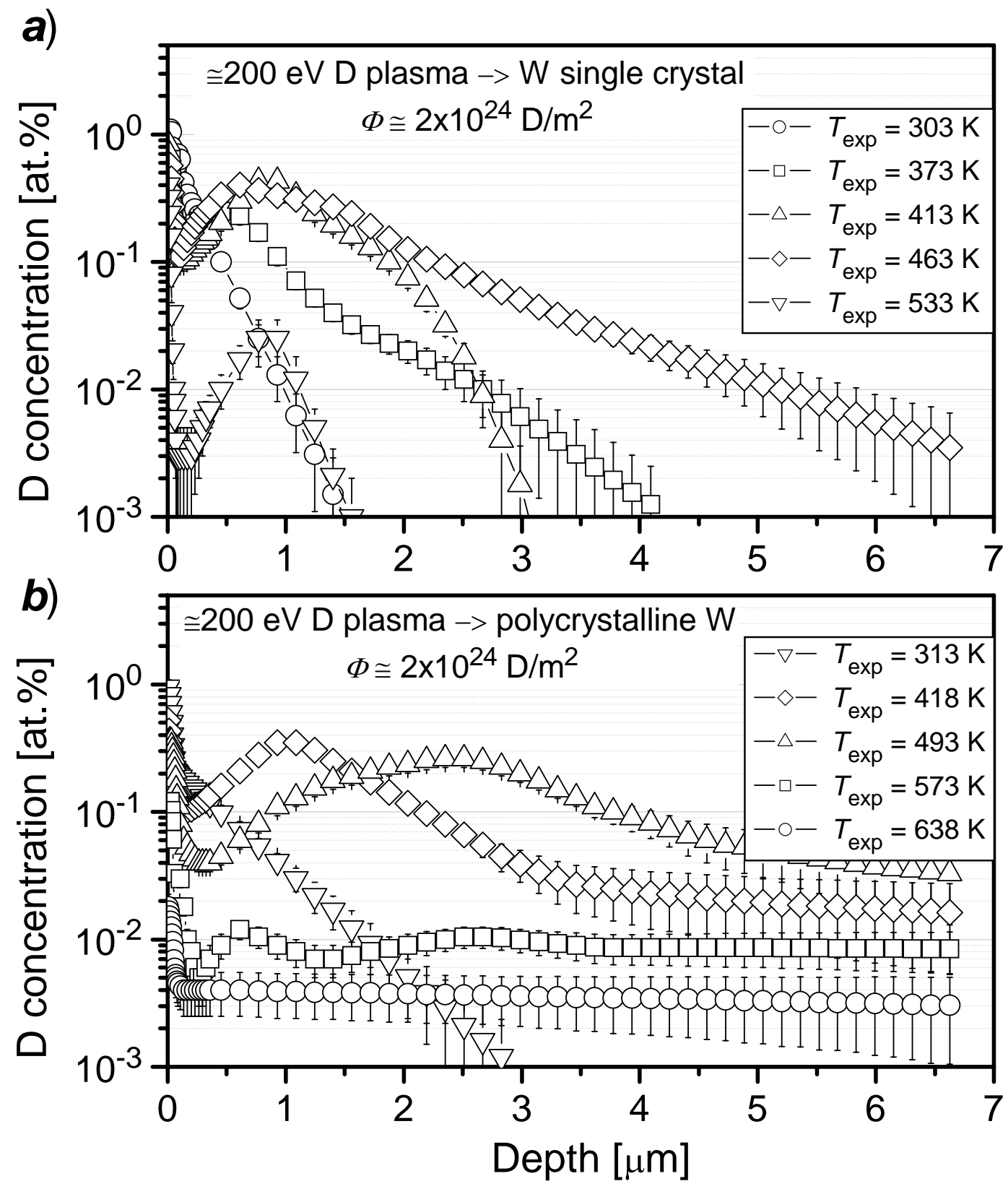

Fig. 8. Depth profiles of deuterium trapped in W single crystal (a) and polycrystalline finegrained W (b) exposed to a low-energy $(\approx 200 \mathrm{eV} / \mathrm{D})$ and high-flux $\left(\approx 10^{21} \mathrm{~m}^{-2} \mathrm{~s}^{-1}\right)$ deuterium plasma to a fluence of about $2 \times 10^{24} \mathrm{D} / \mathrm{m}^{2}$ at various temperatures. 


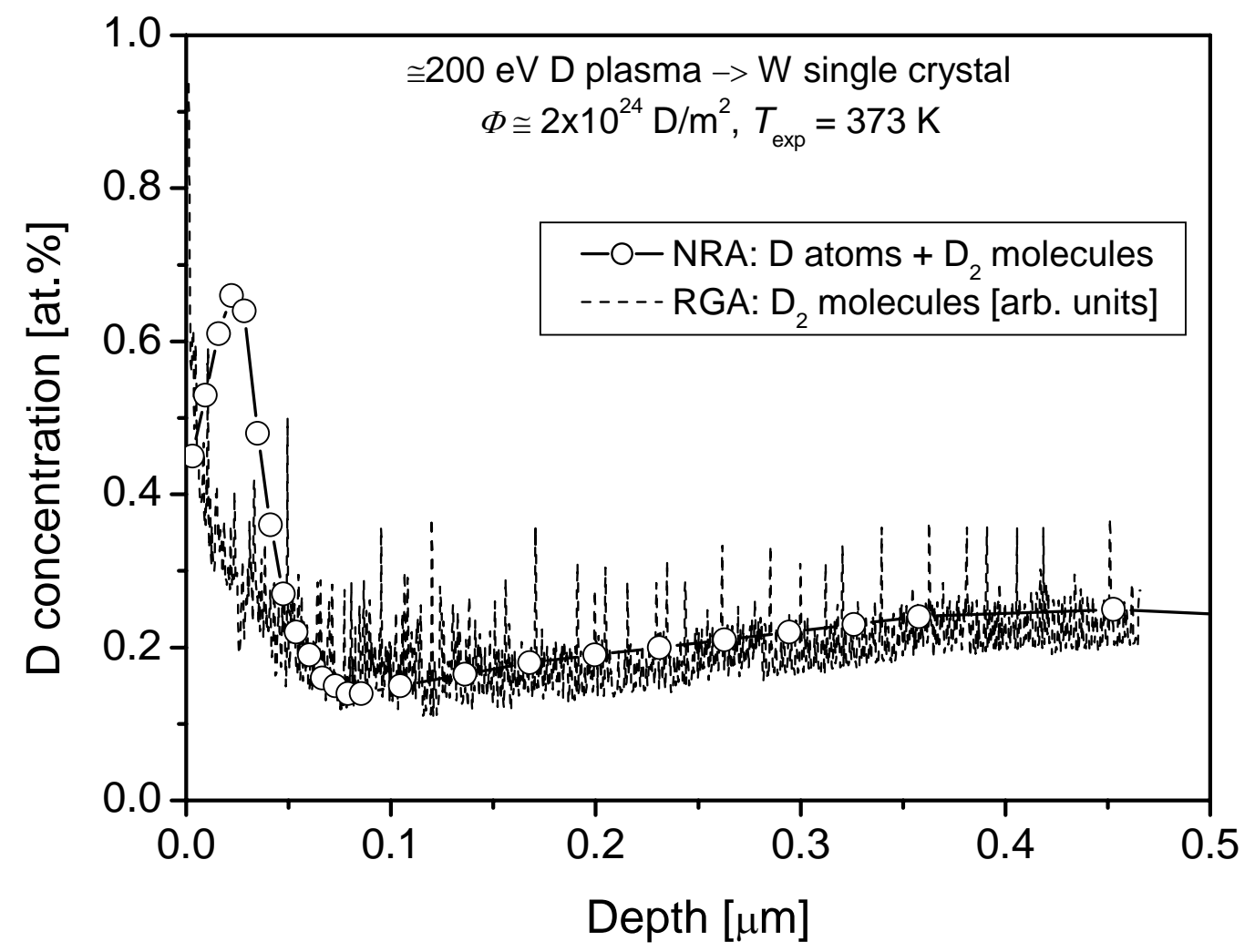

Fig. 9. Depth profile of deuterium in W single crystal exposed to a low-energy ( $\approx 200 \mathrm{eV} / \mathrm{D})$ and high ion flux $\left(\approx 10^{21} \mathrm{~m}^{-2} \mathrm{~s}^{-1}\right) \mathrm{D}$ plasma to a fluence of about $2 \times 10^{24} \mathrm{D} / \mathrm{m}^{2}$ at $373 \mathrm{~K}$ as measured with the $\mathrm{D}\left({ }^{3} \mathrm{He}, \alpha\right) \mathrm{H}$ nuclear reaction (NRA) and with the sputter-residual gas analysis technique (RGA). Note that the concentration of $\mathrm{D}_{2}$ molecules (RGA measurement) is given in arbitrary units. 


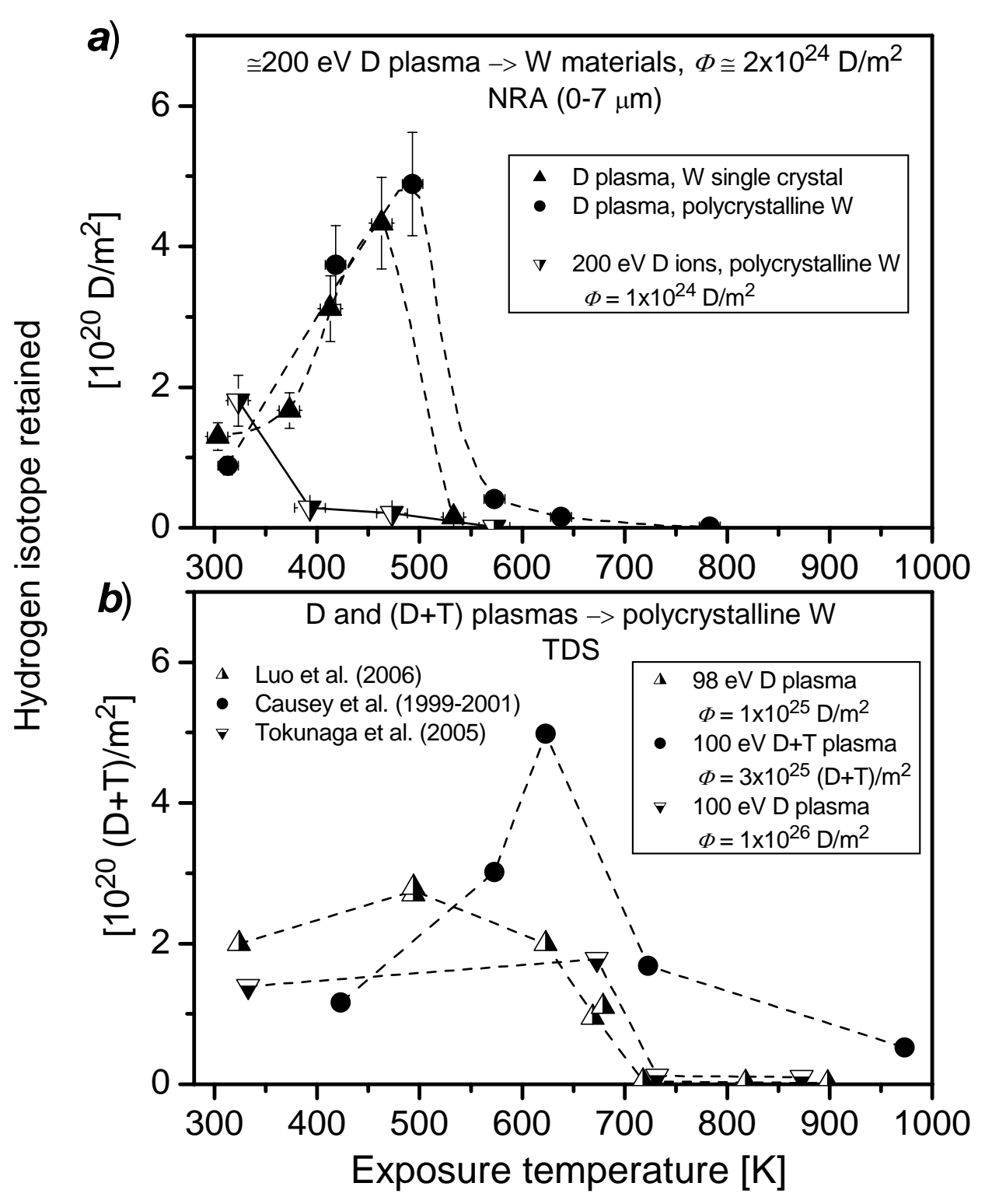

Fig. 10. a) Deuterium retention in single-crystalline and polycrystalline fine-grained tungsten exposed to the low-energy ( $\approx 200 \mathrm{eV} / \mathrm{D}$ ) and high flux (about $1 \times 10^{21} \mathrm{D} / \mathrm{m}^{2} \mathrm{~s}$ ) D plasma as a function of the exposure temperature. For comparison, the temperature dependence of the D retention in polycrystalline coarse-grained W irradiated with $200 \mathrm{eV} \mathrm{D}$ ions and flux of $4 \times 10^{19} \mathrm{D} / \mathrm{m}^{2} \mathrm{~s}$ to a fluence of $1 \times 10^{24} \mathrm{D} / \mathrm{m}^{2}$ is also shown. Note the deuterium retention was calculated from deuterium depth profiles measured up to a depth of $7 \mu$ m.

b) Deuterium retention in polycrystalline tungsten exposed to low-energy (98-100 eV/D(T)) and high flux $\left((8.7-10) \times 10^{21} \mathrm{D}(\mathrm{T}) / \mathrm{m}^{2} \mathrm{~s}\right) \mathrm{D}$ or $(\mathrm{D}+\mathrm{T})$ plasmas as a function of the exposure temperature. Data are taken from Refs. [9-12]. The deuterium retention was examined by TDS. 


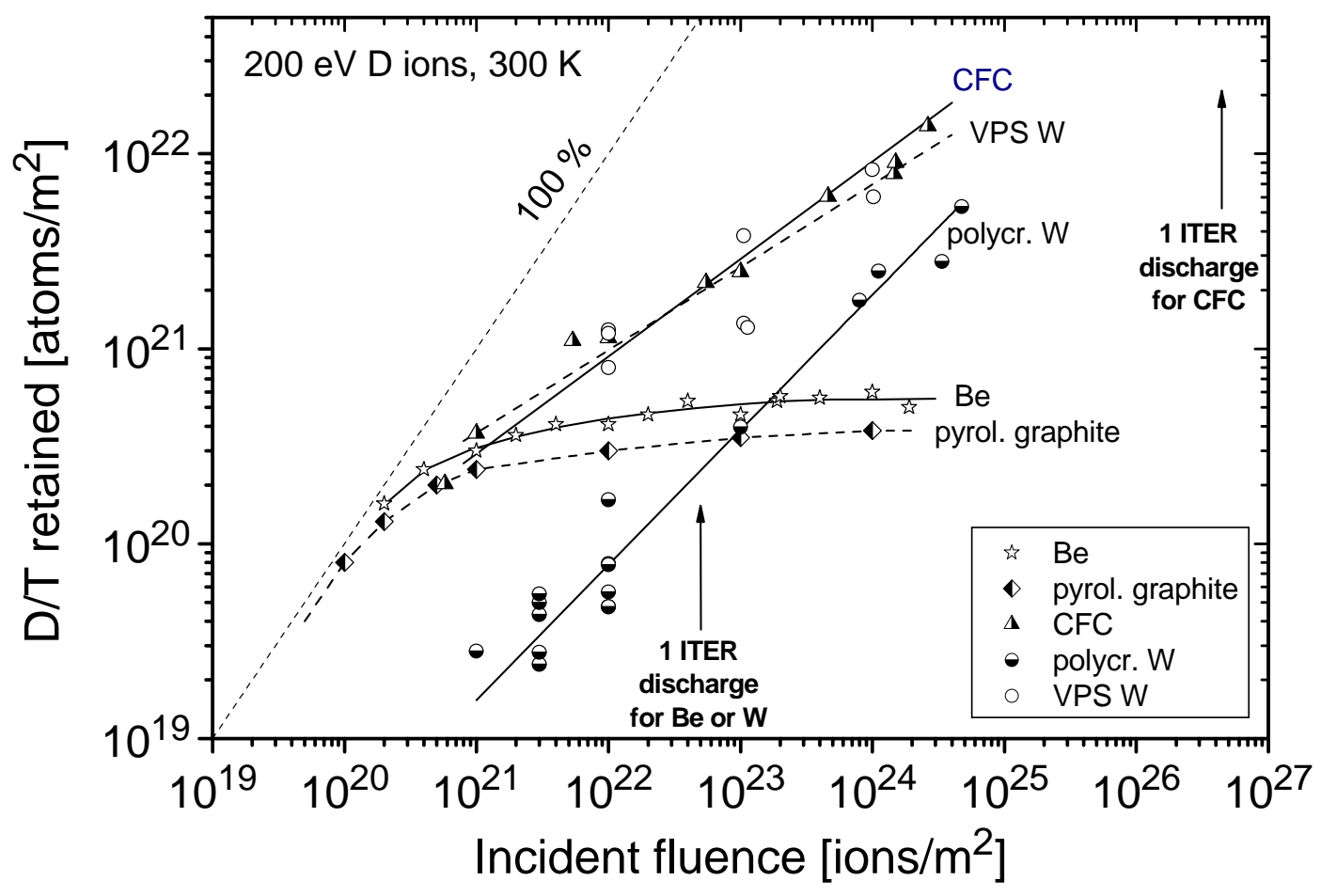

Fig. 11. Deuterium retention in pyrolytic graphite and CFC materials, polycrystalline and vacuum plasma sprayed (VPS) tungsten, and beryllium irradiated with $200 \mathrm{eV}$ D ions at room temperature as a function of incident ion fluence. The data for Be are taken from Ref. [1] and from recent measurements [30]. Arrows indicate expected $\mathrm{D} / \mathrm{T}$ ion fluences incident on areas covered with Be, W and CFC materials, respectively, during one ITER discharge. 